\title{
Effects of dietary flaxseed oil on the muscle fatty acid composition in Mangalitsa pigs in an extensive rearing system
}

\author{
M. Habeanu ${ }^{1 \#}$, N. Lefter ${ }^{1}$, A. Gheorghe ${ }^{1}$, Al. Nagy $^{2}$, D. Marin ${ }^{1}$ \& M. Ropota ${ }^{1}$ \\ ${ }^{1}$ National Research Development Institute for Animal Biology and Nutrition Balotesti. Calea Bucuresti \\ nr.1, 077015 Balotesti, Ilfov, Romania \\ ${ }^{2}$ Station for Agricultural Research Development, Turda, 27, Romania
}

(Received 24 January 2013; Accepted 12 July 2014; First published online 15 August 2014)

\author{
Copyright resides with the authors in terms of the Creative Commons Attribution 2.5 South African Licence. \\ See: http://creativecommons.org/licenses/by/2.5/za \\ Condition of use: The user may copy, distribute, transmit and adapt the work, but must recognise the authors and the South African \\ Journal of Animal Science.
}

\begin{abstract}
The aim of this study was to investigate the effects of dietary flaxseed oil on the fatty acid (FA) composition of two types of muscles, longissimus dorsi (LD) and semitendinosus (ST), of Mangalitsa pigs reared in an extensive system. Fourteen Mangalitsa castrated pigs, $55 \pm 8 \mathrm{~kg}, 240 \pm 12$ days of age, were randomly assigned for a 35-d experimental period to two isoenergetic and isonitrogenous diets, namely a control (C) diet, and an experimental (E) diet with the additional inclusion of $30 \mathrm{~g}$ flaxseed oil/ $/ \mathrm{kg}$. The fatty acid profiles of the flaxseed oil diet, flaxseed oil and the LD and ST muscles were determined by gas chromatography. The $\alpha$-linolenic (ALA) fatty acid content of the flaxseed oil amounted to $41.88 \%$ of the total fatty acid methyl ester (FAME), resulting in an increased deposition of ALA in the LD muscle (2.07 times) and in the ST muscle (2.22 times) when compared with the control group. This effect is associated with the presence of eicosapentaenoic (EPA), docosapentaenoic (DPA) and docosahexaenoic (DHA) fatty acids, which are beneficial to the health of human beings. Additionally, the $n-6: n-3$ ratio of the polyunsaturated fatty acids (PUFA) in the LD muscle (4.60: 1 in the flaxseed diet, compared with $10.16: 1$ in the control diet) are very close to the $n-6: n-3$ requirements $(<5: 1)$ of human. The results of this study indicated that flaxseed oil was a suitable nutritional solution to improving the fatty acid profile of specific muscles of indigenous Mangalitsa pigs.
\end{abstract}

Keywords: $\mathrm{n}-3$ fatty acids, open house rearing, plant oil, pork quality

\# Corresponding author: mihaela.habeanu@ibna.ro

\section{Introduction}

The Mangalitsa pig breed is one of the oldest breeds in Europe, having been recorded for the first time in the 1830s. Mangalitsa pigs are rustic animals and adapt easily to an extensive rearing environment. However, the only inconvenience is that they belong to the fatty morpho-productive type, with low production performance efficiencies. Carcass/meat fatty acids (FA) are key elements that control meat quality and have a primordial role in the nutritional feeding value of the meat (Wood et al., 2008). The effects of the flaxseed oil dietary lipids, with a rich concentration of n-3 fatty acids and of conjugated linoleic acids (CLA), beneficial to human health (Weiss et al., 2004; Habeanu et al., 2014), have received a great deal of public attention in recent years (Mahecha et al., 2009; Riediger et al., 2009). Various authors (Nuernberg et al., 2005; Habeanu et al., 2009) have illustrated the possibility of increasing the n-3 FA concentration in animal tissues by using dietary lipid sources such as fish oil, flaxseed oil and camelina oil. The flaxseed oil dietary fatty acid profile is the main factor that may influence the deposition and structure of meat lipids (Kloareg et al., 2007). Wijendran \& Hayes (2004) illustrated that the nutritional recommendations of humans can be changed by reducing the consumption of linoleic fatty acid (LA), and increasing the consumption of a-linolenic acid (ALA). A low ratio $(<5: 1)$ of n-6 LA : n-3 ALA may have beneficial effects on human health (Mahecha et al., 2009). Flaxseed oil is regarded as an alternative lipid source to fish oil (Nuernberg et al., 2005) since its FA profile favours the deposition of ALA. Little is known about the effect of supplemental flaxseed oil as an ALA source of essential fatty acids, which is a biologic precursor of omega-3 FA, such as eicosapentaenoic acid (EPA), on the lipid structure of tissues in the Mangalitsa pigs. 
The aim of this study was to investigate the effects of flaxseed oil on the FA composition of two types of muscles, namely the longissimus dorsi (LD) and semitendinosus (ST) in Mangalitsa pigs reared under an extensive production system.

\section{Material and Methods}

Animals were treated in accordance with Romanian Law 305/2006 for handling and protecting animals used for experimental purposes.

The experiment was conducted for 35 days during winter on 14 Mangalitsa castrated pigs, $55 \pm 8 \mathrm{~kg}$, aged $240 \pm 12$ days, of the "red colour" variety, at the Turda Research and Development Centre, using an extensive open-house rearing system. The animals were assigned randomly to two groups: A control group ( $C$ diet; $n=7$ ) received a diet with maize $(46 \%)$, barley $(16 \%)$, peas $(25 \%)$, soybean meal $(8.6 \%)$, and a supplement (4.42\%) containing synthetic amino acids, calcium carbonate, monocalcium phosphate, choline premix, salt and a vitamin-mineral premix. The diet of the experimental group (flaxseed oil diet; $n=7$ ) contained the same ingredients, but in different proportions (maize $30 \%$, barley $31.8 \%$, peas $21 \%$, soybean meal $10 \%, 4.2 \%$ supplement) and an inclusion of flaxseed oil (3\%) to ensure the same energy-protein level in both diets. Diets were formulated to meet all nutritional requirements (NRC, 1988): $151.8 \mathrm{~g} \mathrm{CP} / \mathrm{kg}, 13.36$ $\mathrm{MJ} \mathrm{ME} / \mathrm{kg}$ for group C, and 13.37 MJ ME/kg diet for group E, $18.8 \mathrm{~g}$ crude fibre $/ \mathrm{kg}$ for group C, and $65.6 \mathrm{~g}$ crude fibre/kg and the same levels of essential amino acids, calcium and phosphorus. The experimental diet with flaxseed oil containd a high concentration (22.07\%) of C18:3 n-3 and a ratio of $1.72: 1$ of LA : ALA. The animals had free access to feed and water in the house. The dietary fatty acid profile of flaxseed oil and the control (C) and experimental (E) diets are presented in Table 1.

Table 1 Fatty acids profile of flaxseed oil diet and flaxseed oil used during the experiment

\begin{tabular}{lccc}
\hline $\begin{array}{l}\text { Fatty acids } \\
\text { (\% of the total FAME*) }\end{array}$ & Control diet & Experimental diet & Flaxseed oil \\
\hline C14:0 (myristic) & 0.09 & 0.07 & 0.06 \\
C16:0 (palmitic) & 12.10 & 9.98 & 5.91 \\
C16:1 (palmitoleic) & 0.14 & 0.09 & 0.15 \\
C18:0 (stearic) & 2.78 & 3.32 & 2.99 \\
C18:1cis-9 (oleic) & 23.68 & 26.40 & 20.75 \\
C18:2n-6 (linoleic) & 54.57 & 38.00 & 27.04 \\
C18:3n-3 (a-linolenic) & 5.86 & 22.07 & 41.88 \\
C18:2n-6 : C18:3n-3 (LA : ALA) & 9.31 & 1.72 & 0.64 \\
\hline
\end{tabular}

*FAME = fatty acid methyl esters.

The protein, fat, ash and fibre contents of the diet were determined with standardized methods according to Commission Regulation (EC) no. 152 (2009). The crude protein content was determined with the Kjeldahl method, which involved the decomposition of the feed sample by heating with sulphuric acid, in the presence of catalysts, to reduce the organic nitrogen to ammonium ions that can be determined by distillation followed by titration, using the semiautomatic Kjeltec Auto 2300 system (Tecator, Sweden). The crude fat was determined by extraction with organic solvents, obtaining an "ether extract", using the automatic Soxtec 2055 system (Tecator, Sweden). The crude fibre was determined by intermediary filtration, using the Fibertec 2010 system (Tecator, Sweden). The gravimetric method was used for ash, using a Caloris CL 1206 laboratory furnace. Fourteen samples of $150 \pm 50 \mathrm{~g}$ from each of the LD $(n=14)$ and the ST $(n=14)$ muscles were collected at slaughtering at the end of the experiment to determine the fatty acid composition by gas chromatography according to the method described by Habeanu et al. (2011). After lipid extraction from the samples, the FAs were transformed into methyl esters by transmethylation, and the components were separated in the capillary chromatograph column. The fatty acids were identified by comparison with blank chromatograms, and were subsequently determined quantitatively as percentages. Supelco 37 component FAME mix was used; $10 \mathrm{mg} / \mathrm{mL}$ as standard solution of methylated fatty acids, also soybean oil, and sunflower oil; Supelco was used as reference material. A Perkin Elmer-Clarus 500 gas chromatograph was used, fitted with a system of injection into the capillary column (splitting ratio about 1 : 100), with programmed chromatographic column oven heating; the system was fitted with flame ionization 
detector (FID) and column of high polarity stationary capillary separation (SGE forte GC capillary column BPX70, $60 \mathrm{~mL} ; 0.25 \mathrm{~mm}$ inner diameter, $0.25 \mathrm{um}$ gros.film). Hydrogen was used as the carrier gas and the air oxygen as burning gas. The methylated fatty acids from the sample were separated according to chain length, to the level of unsaturation and to the geometry of the double bonds. A control sample (n-hexane) and a reference sample (CRM) were analysed in parallel with the analysed sample (or batch of samples).

The results were expressed as average values and standard error of mean (SEM). The values for FA are expressed as percentage (\% of the total fatty acid methyl esters). The data were submitted to variance analysis with SPSS 12 software 2003 ANOVA general linear model (GLM) and the averages were compared using the Tukey HSD test at $\alpha=5 \%, \alpha=1 \%$ and $\alpha=0.1 \%$ significance levels. The general linear model (GLM) test allowed the researchers to determine the significance of the effect of the two factors (muscle and diet), as well the interaction of diet $x$ muscle.

\section{Results and Discussion}

Table 2 Fatty acids composition (\% of total fatty acid methyl esthers) of the longissimus dorsi and the semitendinosus muscles of finishing Mangalitsa pigs given control ( $C$ diet) and flaxseed oil ( $E$ diet) during the 35 days

\begin{tabular}{|c|c|c|c|c|c|c|c|c|}
\hline \multirow{2}{*}{$\begin{array}{l}\text { Fatty acids* } \\
\text { (\% of total FAME) }\end{array}$} & \multicolumn{2}{|c|}{ Longissimus dorsi } & \multicolumn{2}{|c|}{ Semitendinosus } & \multirow[b]{2}{*}{ SEM } & \multirow{2}{*}{$\begin{array}{l}\text { Muscle } \\
\text { effect }\end{array}$} & \multirow{2}{*}{$\begin{array}{l}\text { Diet } \\
\text { effect }\end{array}$} & \multirow{2}{*}{$\begin{array}{c}\text { Muscle } x \\
\text { diet }\end{array}$} \\
\hline & Control & $\begin{array}{l}\text { Flaxseed } \\
\text { oil }\end{array}$ & Control & $\begin{array}{l}\text { Flaxseed } \\
\text { oil }\end{array}$ & & & & \\
\hline C14:0 (myristic) & 1.62 & 1.62 & 1.14 & 1.24 & 0.05 & $<0.001$ & NS & NS \\
\hline C16:0 (palmitic) & 25.35 & 25.32 & 22.08 & 23.01 & 0.38 & $<0.001$ & NS & NS \\
\hline C16:1 (palmitoleic) & 3.30 & 3.29 & 3.76 & 3.77 & 0.18 & NS & NS & NS \\
\hline C18:0 (stearic) & 12.06 & 11.83 & 10.09 & 10.16 & 0.25 & $<0.001$ & NS & NS \\
\hline C18:1cis-9 (oleic) & 41.70 & 42.87 & 42.44 & 41.19 & 0.43 & NS & NS & NS \\
\hline C18:2n-6 (linoleic) & 11.47 & 9.62 & 12.55 & 12.56 & 0.44 & 0.015 & NS & NS \\
\hline C18:3n-3 (a linolenic) & 0.91 & 1.88 & 0.72 & 1.60 & 0.12 & NS & $<0.001$ & NS \\
\hline $\begin{array}{l}\text { CLA (Conjugated } \\
\text { linoleic acid) }\end{array}$ & 0.50 & 0.80 & 0.71 & 0.64 & 0.03 & NS & NS & 0.017 \\
\hline C20:4n-6 (arachidonic) & 0.23 & 0.06 & 2.46 & 1.80 & 0.23 & $<0.001$ & NS & 0.004 \\
\hline C20:5n-3 (EPA) & 0 & 0.03 & 0.09 & 0.26 & 0.02 & $<0.001$ & $<0.001$ & 0.008 \\
\hline C22:5n-3 (DPA) & 0 & 0.03 & 0.26 & 0.16 & 0.02 & $<0.001$ & $<0.001$ & 0.009 \\
\hline C22:6n-3 (DHA) & 0 & 0.10 & 0.24 & 0.39 & 0.03 & $<0.001$ & 0.02 & NS \\
\hline \multicolumn{9}{|l|}{ Total concentration } \\
\hline Total SFA & 39.14 & 38.72 & 33.38 & 34.41 & 0.66 & $<0.001$ & NS & NS \\
\hline Total MUFA & 46.06 & 47.04 & 47.86 & 46.39 & 0.45 & NS & NS & NS \\
\hline Total PUFA & 13.69 & 13.35 & 17.72 & 17.96 & 0.64 & $<0.001$ & NS & NS \\
\hline Total n-6 PUFA & 12.49 & 10.97 & 15.99 & 15.27 & 0.59 & $<0.001$ & NS & NS \\
\hline Total n-3 PUFA & 1.20 & 2.37 & 1.72 & 2.68 & 0.15 & 0.03 & $<0.001$ & NS \\
\hline$E P A+D P A+D H A$ & 0 & 0.16 & 0.59 & 0.81 & 0.08 & $<0.001$ & 0.009 & NS \\
\hline C18:2 n-6/ C18:3n-3 & 12.60 & 5.12 & 17.43 & 7.85 & 1.11 & $<0.001$ & $<0.001$ & NS \\
\hline Ratio $n-6: n-3$ & 10.41 & 4.62 & 13.53 & 7.84 & 0.77 & $<0.001$ & $<0.001$ & NS \\
\hline Ratio PUFA : SFA & 0.34 & 0.35 & 0.52 & 0.53 & 0.02 & $<0.001$ & NS & NS \\
\hline $\begin{array}{l}\text { * FAME = fatty acid met } \\
\text { Total MUFA (total mono } \\
\text { Total PUFA (total poly } \\
\text { C20:5n-3 + C22-5 n-3 + } \\
\text { Total n-6 PUFA = C18:2 } \\
\text { n-3 + C22:6n-3. } \\
\text { The following fatty acids } \\
\text { C20:2n-6. NS: not signif }\end{array}$ & $\begin{array}{l}\text { Insaturatec } \\
\text { n-6 + } 622 \text { - } 20 \\
\text { have bee }\end{array}$ & 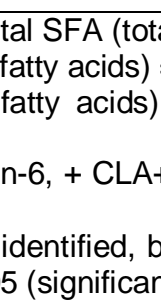 & $\begin{array}{l}14: 1 ; C \\
\text { C18:2n- } \\
\text { 20:4n-6; } \\
\text { not inclu }\end{array}$ & $\begin{array}{l}\text { C18:3n } \\
\text { al n-3 PU }\end{array}$ & $\begin{array}{l}14.0 \\
18: 1 n \\
+\quad C 1\end{array}$ & $\begin{array}{l}16: 0+C \\
\text {-18:1n-1 } \\
\text { n-3; C20 } \\
n-3+C 1\end{array}$ & $\begin{array}{l}18: 0 ; \\
+\mathrm{CLA} \\
+\mathrm{C} 2\end{array}$ & $\begin{array}{l}20: 4 n-6+ \\
3+C 22-5 \\
C 18: 4 n-3\end{array}$ \\
\hline
\end{tabular}


Previous studies have shown that the LD and the ST muscle are oxido-glicolytic (Gentry et al., 2004; Chriki et al., 2012), varying by their fat content (Habeanu et al., 2014). In this study, the fat content of the LD $(22.5 \%)$ and the ST $(5.17 \%)$ muscles varied by $77 \%$. Table 2 shows the centesimal FA composition of the LD and the ST muscles from the two experimental dietary treatments. The predominant FA ( $>41.19 \%$ of the total FA) in both types of muscle was the monounsaturated oleic FA (C18:1 cis 9).

The total PUFA concentration was affected by the flaxseed oil dietary treatment not only by the muscle type. The total n-3 PUFA was affected by both the flaxseed oil dietary inclusion and muscle type. The concentration of total n-3 PUFAs was higher in both types of muscle when the flaxseed oil diet was supplemented with flaxseed oil, but the effect was more pronounced in the ST muscle $(2.68 \%$ in the ST muscle vs. $2.37 \%$ in the LD muscle). The increase of n-3 FA concentration when flaxseed oil was added to the diet was associated with a significant $(P<0.001)$ decrease of the arachidonic acid concentration in both types of muscle. The total n-6 PUFA was higher $(P<0.001)$ in the ST muscle $(15.27 \%$ flaxseed oil diet and $15.99 \%$ for the control diets, respectively) compared with the LD muscle $(10.97 \%$ to $12.49 \%)$. $\mathrm{H}$, the flaxseed dietary oil treatment had no effect. This level of total n-6 PUFA is much higher than that (5.55\% - 5.61\%) reported by Parunovic et al. (2012) in different rearing systems (conventional vs. free range), probably because of the use of a soya protein concentrate with fish oil as a source of n-3 FA for that particular study.

Alpha-linolenic fatty acid concentration was not affected by muscle type, but was influenced ( $P$ $<0.001$ ) by dietary treatment. Distribution ALA was 1.2 times higher in the LD muscle than in the ST muscle. The ALA of flaxseed oil diet was 2.14 times higher than that in the $C$ diet. The failure to identify FAs derived from ALA, such as EPA, DPA and DHA in the LD muscle of the C diet, was important. The content of ALA was 3.5 times and 12 times higher than that determined by Parunovic et al. (2012) in Mangalitsa pigs. Longchain n-3 PUFA (EPA, DPA, DHA) showed a higher $(P<0.001)$ deposition in the ST muscle $(1.4 \%)$ than the LD muscle $(0.16 \%)$, probably because these longer chain FAs are synthesized from ALA by an enzymatic pathway. These FAs are influenced both by the muscle type and by the flaxseed oil dietary treatment and there is a significant interaction between muscle types $x$ dietary treatment (except in DHA). These precursors of ALA play an important role in the control of cardiovascular diseases (Givens, 2009) and display antiinflammatory potential because of their traditional properties of inhibiting the formation of n-6 PUFA-derived eicosanoids (Wall et al., 2010). The concentration of EPA + DPA + DHA is higher in the flaxseed oil diet ST muscle $(0.81 \%)$ than in the flaxseed oil diet LD muscle $(0.16 \%)$.

The concentration of linoleic FA, as predominant n-6 PUFA, was higher in the ST muscle (12.55\% and $12.56 \%$, respectively) compared with the LD muscle (11.47\% and $9.62 \%$, respectively).

The ratio $n-6: n-3$ was 1.42 times lower in the LD muscle than in the ST muscle, and the ratio C18:2 n-6/C18:3 n-3 was 1.42 times lower in the LD muscle than in the ST muscle, probably because the LD muscle is more oxidative (Chriki et al., 2012) owing to the predominance of I-type fibres in the outdoor rearing system (Gentry et al., 2004; Graziotty et al., 2009). The n-6 : n-3 ratio of both the LD and the ST muscles decreased significantly in the flaxseed oil diet compared with the control group, reaching a level that can be beneficial for human health in the LD muscle (4.60\% vs. $10.16 \%)$. However, the ratio of total $n-6$ PUFA : total n-3 PUFA, (37.3:1) in the conventional rearing system and $9.2: 1$ in the free-range system, as reported by Parunovic et al. (2012), is higher than that observed during the present study, particularly in the group with supplemental flaxseed oil (4.62 in the LD muscle and 5.69 in the ST muscle of the experimental diet).

In this study, the SFA represented a lower proportion (33\% - 39\%) from the total FA compared with the mono- and polyunsaturated FA $(59 \%-66 \%)$. The differences in terms of SFA were not significant $(P>0.05)$ between dietary treatment groups. However, differences $(P<0.001)$ in total SFA content were recorded between muscle types. The decrease in C16:0 in the ST muscle was not affected by the flaxseed oil diet, but by the muscle type $(<1.12$ times than the LD muscle, $P<0.0001)$. The flaxseed oil diet does not have an effect on the C18:0 concentration of the muscle, but the muscle type does have a significant effect $(P<0.001)$ on this FA. That is according to data reported by Habeanu et al. (2011) when $11 \%-13 \%$ camelina oil was fed to finishing Large White pigs. The interaction muscle $x$ diet was not significant except for CLA, C20:4n-6, EPA, DPA FA.

\section{Conclusions}

Flaxseed oil was a suitable nutritional solution for improving the lipid structure of meat from Mangalitsa pigs. The supplemental flaxseed oil used as rich source of $n-3$ fatty acids in the diet for finishing Mangalitsa pigs favoured the retention of $n-3$ fatty acids, mostly ALA. This effect is associated with the presence of EPA, DPA and DHA, particularly in the ST muscle, and by a lower n- $6: n-3$ ratio, particularly in the LD muscle. 


\section{Acknowledgments}

This work was financed by the project Nucleus Programme PN 09380401: "Development of research in biology and animal nutrition to increase competitiveness of the livestock sector".

\section{References}

Chriki, S., Picard, B., Jurie, C., Reichstadt, M., Micol, D., Brun, J.P., Journaux, L. \& Hocquette, J-F., 2012. Meta-analysis of the comparison of the metabolic and contractile characteristics of two bovine muscles: Longissimus thoracis and semitendinosus. Meat Sci. 91, 423-429.

Gentry, J.G., McGlone, J.J., Miller, M.F. \& Blanton, J.R., 2004. Environmental effects on pig performance, meat quality, and muscle characteristics. J. Anim. Sci. 82, 209-217.

Givens, I., 2009. Animal nutrition and lipids in animal products and their contribution to human intake and health. Nutrients 1, 71-82.

Graziotty, G.H., Rios, C.M., Menendez, J.M.R., Salinas, M.A., Bosco, A., Ceschel, A.P., Affricano, N.O. \& Victorica, C.L., 2009. Muscular partitioning in the semitendinosus muscle of the pig. Int. J. Morphol. 27, 947-953.

Habeanu, M., Hebean, V., Taranu, I., Marin, D., Ropota, M. \& Tamas, V., 2009. Effects of dietary camelina oil on Large White pigs meat quality. Archiva Zootechnica. 12, 31-46.

Habeanu, M., Hebean, V., Taranu, I., Ropota, M., Lefter, N. \& Marin, D., 2011. Dietary ecologic camelina oil - a beneficial source of n-3 PUFA in muscle tissue and health status in finishing pigs. Rom. Biotech. Lett. 16, 5564-5571.

Habeanu, M., Thomas, A., Bispo, E., Gobert, M., Gruffat, D., Durand, D. \& Bauchart, D., 2014. Extruded linseed and rapeseed both influenced fatty acid composition of total lipids and their polar and neutral fractions in longissimus thoracis and semitendinosus muscles of finishing Normand cows. Meat Sci. 96, 99-107.

Kloareg, M., Noblet, J. \& Van Milgen, J., 2007. Deposition of dietary fatty acids, de novo synthesis and anatomical partitioning of fatty acids in finishing pigs. Br. J. Nutr. 97, 35-44.

Mahecha, L., Nuernberg, K., Nuernberg, G., Ender, K., Hagemann, E. \& Dannenberger, D., 2009. Effect of diet and storage on FA profile, micronutriments and quality of muscle from German Simmental bulls. Meat Sci. 82, 365-371.

NRC, 1998. Nutrient Requirements of Swine (10 th ed.). National Academy Press, Washington D.C., USA. pp. 111.

Nuernberg, K., Klaus, F., Nuernberg, G., Kuechenmeister, U., Klosowska, D., Eliminowska-Wenda, G., Fiedler, I. \& Ender, K., 2005. Effect of dietary olive flaxseed oil on lipid composition, meat quality, sensory characteristics and muscle structure in pigs. Meat Sci. 70, 63-74.

Official Journal of the European Union L 54, 2009. Commission Regulation (EC) No. 152/2009 laying down the methods of sampling and analysis for the official control of feed.

Parunovic, N., Petrovi, M., Matekalo-Sverak, V., Trbovi, D., Mijatovi, M. \& Radovic, C., 2012. Fatty acid profile and cholesterol content of $\mathrm{m}$. longissimus of free-range and conventionally reared Mangalitsa pigs. S. Afr. J. Anim. Sci. 42, 101-113.

Riediger, N.D., Othman, R.A., Suh, M. \& Moghadasian, H.M., 2009. A systemic review of the roles of n-3 FA in health and disease. J. Am. Diet. Assoc. 109, 668-679.

SPSS, 2003. Statistics 12. INC. USA.

Wall, R., Ross, R.P., Fitzgerald, G.F. \& Stanton, C., 2010 Fatty acids from fish: the anti-inflammatory potential of long-chain omega-3 fatty acids. Nutr. Rev. 68, 280-289.

Weiss, M., Martz, F.A. \& Lorenzen, C.L., 2004. Conjugated linoleic acid: Implicated mechanisms related to cancer, atherosclerosis and obesity. The Professional Animal Scientist 20, 127-135.

Wijendran, V. \& Hayes, K.C., 2004. Dietary n-6 and n-3 fatty acid balance and cardiovascular health. Ann. Rev. Nutr. 24, 597-615.

Wood, J.D., Enser, M., Fisher, A.V., Nute, G.R., Sheard, P.R., Richardson, R.I., Hughes, S.I. \& Whittington, F.M., 2008. Fat deposition, fatty acid composition and meat quality: A review. Meat Sci. 78, 343-358. 